They report that three out of eight submarine basalts obtained from Pacific Ocean deep sea mounts exhibit self-reversal properties under certain conditions. Saturation magnetization measurements show that each of the three specimens contains, in its virgin state, a single magnetic component with a Curie point of $250^{\circ} \mathrm{C}$. On heating to $400^{\circ} \mathrm{C}$, this component is partially converted to a new magnetic phase possessing a Curie point of $300^{\circ} \mathrm{C}$. Heating to even higher temperatures produces a single phase having a Curie point of $560^{\circ} \mathrm{C}$.

What is significant, however, is that if one of these specimens is heated to any temperature between $300^{\circ} \mathrm{C}$ and $330^{\circ} \mathrm{C}$ for a few minutes, and then re-cooled in the geomagnetic field, the resulting magnetization is antiparallel to the field. The reason is that the unconverted part of the primary magnetic phase, of Curie point $250^{\circ} \mathrm{C}$, interacts magnetically with the newly produced component of higher Curie point to produce a net reversed moment. Below $300^{\circ} \mathrm{C}$ there is insufficient new material for this to occur, and above $330^{\circ} \mathrm{C}$ not enough virgin phase remains; but as long as the temperature of the specimen is not maintained at $300^{\circ} \mathrm{C}$ to $330^{\circ} \mathrm{C}$ for too long a time, the balance of old to new material is just correct for the interaction to occur. Nor is this merely a low magnetic field phenomenon, for fields of up to 2,600 oersteds are insufficient to suppress the self-reversal.

One may argue, of course, that the laboratory processes used by the Ozimas to produce self-reversal over a limited temperature range rarely occur in nature supported by the fact that virgin specimens still contained only the low Curie point magnetic phase), and thus that it is unlikely that self-reversal occurred during the production of the natural magnetization. Moreover, the correlations between the linear ocean anomalies and the continental polarity time scale, and between each of these and the reversals patterns in deep sea sediments, are too tight to allow the existence of widespread self-reversal in oceanic basalts. For these reasons the work of the Ozimas is likely to be of greater interest to those concerned with the phenomenon of self-reversal itself.

\section{Carcinogenic Oil Fractions}

Is 1948, it was realized that workers who had been exposed for many years to "cutting oils" applied to the cutting edge of machine tools tended to develop skin cancers. In the same year the Medical Research Council set up a committee on the carcinogenic action of mineral oils under the chairmanship of Professor T. Ferguson. The aim was to carry out an intensive examination of crude oils like those used in industry, in order to isolate and identify the carcinogenic constituents. It was also hoped that methods might be developed for the removal of these carcinogens and that specifications for safe oils might be formulated. Twenty years later the committee's findings have been published by HMSO in No. 306 of the council's special report series, price $£ 2$.

The research was carried out at the universities of Birmingham, Exeter, Glasgow and Leeds, and the University of Manchester Institute of Science and Technology. Biological tests were also carried out at the Chester Beatty Research Institute, and quantita. tive techniques were evolved at the MRC Statistical
Research Unit. Using three crude oils from fields in Kuwait, Oklahoma and Lagunillas, the research consisted first of the fractionation of the oils by physical and chemical means, and second of the biological testing of fractions produced in this way. Rabbits, which were found to be more sensitive to carcinogens in mineral oil than mice, were used in the biological tests.

The principal fractionation techniques used were vacuum distillation, solvent extraction, adsorption chromatography and chemical treatment, and care was taken not to produce permanent chemical changes in the oil constituents. The first exploratory studies led to the isolation of some 45 pure compounds, some of which had not previously been recognized as constituents of crude, uncracked mineral oils, and none of which is known to be markedly carcinogenic. Some of the more complex hydrocarbons isolated from the higher-boiling point fractions were shown to be weakly carcinogenic, and included 4-methyl-1,2-benzanthracene and 7-methyl-1,2-benzanthracene. Other isolated substances approach in complexity the known polycyclic aromatic carcinogens and may contribute to the total carcinogenic activity of the oil. In the biological tests, oil fractions were either painted on or injected subcutaneously into experimental animals which were later examined for tumours. By diluting the fractions to be tested with medicinal liquid paraffin, it was shown convincingly that the carcinogens reside in the aromatic fractions of the oil which can be extracted with acetone or other solvents.

Although the general chemical nature of the active ingredients has been established, the committee has unfortunately failed to develop rapid methods of detecting carcinogens in the oils.

\section{Effect of Densely lonizing Radiation}

\section{from a Correspondent}

Mammalian cells and higher plant cells are more susceptible to damage from densely ionizing radiations, such as $\alpha$-particles or fast neutrons, than from hard $\mathrm{X}$-rays. In more quantitative terms, the relative biological efficiency (RBE) of these radiations compared with hard X-rays is greater than one. The most commonly accepted explanation is that a certain minimum amount of energy deposited in a given length of track is necessary for the production of a biological effect. In this interpretation the effectiveness of hard $\mathrm{X}$-rays is due to the densely ionized tails of the tracks of recoil electrons, or to chance interaction between tracks when large doses are used. Using data on the RBE of deuterons and helium nuclei of various energies on the killing of human kidney cells in vitro, Barendsen (Int. J. Rad. Biol., 8, 453; 1964) estimated that a lethal event was produced when more than about 500 $\mathrm{eV}$ (15 "ionizations") was deposited in a target of about $100 \AA$ thick.

The sensitizing effect of oxygen decreases with increasing "density of ionization", and this effect has been attributed to the same cause. Radicals formed close together along a densely ionized track were thought to interact and produce permanent damage which could not be affected by the presence or absence of oxygen.

Recently, however, Neary (Int. J. Rad. Biol.,9, $477,1965 ; 11,209,1966 ; 12,317,1967)$ has suggested 